\title{
Posttraumatic Growth and Existential Thinking in Young Adults
}

\author{
Sahana V and Dr. Guneet Inder Jit Kaur
}

\begin{abstract}
The study aimed to examine the relationship between posttraumatic growth and existential thinking. The study was conducted on 150 young adults pursuing various professions within the age range of 20-30 years who had undergone some traumatic event in life. The study employed a quantitative research design and the sample was chosen using purposive sampling technique. Posttraumatic growth inventory and scale for existential thinking was used for the purpose of data collection. The obtained data was analysed using Pearson Product-moment correlation. Additionally, linear regression analysis was used. The results of the study indicated a significant positive correlation between posttraumatic growth and existential thinking. The regression analysis suggested further that posttraumatic growth has an impact on existential thinking.
\end{abstract}

Keywords - existential thinking, meaning in life, posttraumatic growth, trauma

\section{INTRODUCTION}

When one hears the term trauma thoughts of negative experiences, and emotions come into the framework. As trauma creates a huge impact in one's life, what is less known is how humans are able to function and move on. Since many years, humans have been pondering on what makes the human life sustain even after experiencing many stressful life event's and trauma has become a shared human nature [1]. Be it young age or old age, many individuals have experienced trauma in life, such as: illness of parent, relationship breakup, bereavement, domestic violence, sexual assault or it might even include bad childhood experience that has affected ones' life in various ways. Traumatic events are different from stressful life events by their attributed seriousness [2]. Traumatic experiences often involve a threat to life or safety, any situation that makes one feel overwhelmed and isolated even if it doesn't involve physical harm. As a result, trauma occurs from an event, series of event, or circumstances that is experienced by the individual as physically or emotionally harmful or threatening and that has a lasting effect on the individual's functioning [3]. Post-trauma period is the most critical stage as it leaves an individual with distressing memories, emotions and anxiety that lasts for longer time [4]. But then, one positive aspect of trauma is that many researchers have addressed the probability of growth followed by a traumatic event [5]-[8]. As growth is observed as an event

Sahana V, Jain University, India

Dr. Guneet Inder Jit Kaur, Jain University, India that makes one interpret the traumatic experience as matured and complete. It is believed that, through the process of struggling with adversity, changes may arise which drives an individual to reach higher level of functioning [9]. One such phenomenon where the individual experiences a positive psychological growth followed by a trauma is known as posttraumatic growth [10]. Reference [11] accentuated positive growth that occur in five domains: (1) Relating to others, (2) new possibilities, (3) personal strength, (4) spiritual change, and (5) appreciation of life. Greater appreciation for life following a trauma represents changes in priorities and taking pleasure in aspects that once were taken for granted. Trauma survivors also experience increased compassion and empathy for others, which makes them involve in deeper and meaningful relationships. The attribute of identifying new possibilities, increased strength, and independence can be observed in trauma survivors who display high levels of posttraumatic growth [12]. Reference [13] suggested that one need not have to have all five domains to have experienced growth, growth in one or two domains could indicate posttraumatic growth and that growth may be in existence with distress.

For posttraumatic growth to occur, many environmental factors such as support from family, interpersonal relationships, society, as well as personal factors such as resilience, optimism, self-confidence and easy-going disposition plays a predominant role in the aftermath of the crisis [14]. Also, trauma survivors ruminate more on traumatic experiences which makes them question, explore on concepts of human existence and their essentials [15]. Reference [16] emphasised that during the process of reconciling with trauma, one's assumptions of the world and self are shattered which makes one contemplate on trauma so immensely that it changes the way one thinks and acts after the traumatic event. Empirical evidences show how positive affect co-occurs with distress in stressful situation as well as class of meaning-based coping mechanisms are involved in the phase of posttraumatic period [17]. Reference [18] suggested that positive illusion such as 'the cognitive tendency of self enhancement, unrealistic optimism, and an exaggerated perception of person control' act as a catalyst to preserve physical and mental health in the periods of trauma or life-threatening circumstances. As one experiences various emotions such as anxiety, sorrow, despair and thoughts like who am I? What is the meaning of life? and contemplate on deeper aspects of life, attempting to 
rebuild the worldview and to adapt to trauma [19]. Martin Heidegger asserts that anxiety resulting from a confrontation of the nothingness in the world aids in moving people into meaning making and afford them the capacity to live freely for themselves [20].

Exploring on the concepts of meaning in life, existence, universe, and mysteries of life such as what happens after death, what is the purpose of life, and discussing about various philosophy or beliefs. Is part of human nature and we all involve in thinking about these existential issues. Reference [21] termed this tendency to explore the fundamental concerns of human existence and the capacity to engage in meaningmaking process that locates oneself in respect to these issues as existential thinking. The ultimate concerns of the human existence relate to one's relation to the grand organization of the cosmos, such as the nature of reality, as well as the most fundamental, inescapable parts of human conditions, such as the meaning in life and inevitability of death [5]. Thus, existential thinking is concerned with aspirations beyond the self [22]. Meaning-making is the central tenet of coping [23], [24]. Recognizing meaning amidst trauma and its aftermath may allow a person to experience emotional relief, lead to new philosophy of life that alters individual's assumptions about the people, world and contemplating on the meaning it might have [25], [26]. Viktor E. Frankl, an Austrian psychiatrist in his book Man's search for Meaning emphasized on searching for meaning as one of the basic and high-order needs that every human goes through to have optimal functioning [7].

Friedrich Nietzsche [27] says "that which does not kill us, make us stronger" indicating that the adversity an individual endures during his life time, in fact makes the person grow stronger and also posttraumatic growth act as protective factor against suicidal ideations [28]. In fact, Albert Camus conveyed that individuals experience these when confronted with adverse or traumatic situation. Articulating that there is one serious philosophical question and that is suicide. Camus argues that human beings cannot escape asking questions such as 'what the meaning of existence is?', it is observed in his book, The Myth of Sisyphus, Sisyphus, who was punished by Gods to roll up a rock up the mountain, only to witness that it rolling back down, then descending after the rock to begin all over, in an endless cycle. Camus says that like Sisyphus, humans cannot help but ask questions about meaning of life. He writes, 'There is no sun without shadow, and it is essential to know the night' [29]. Jean-Paul Sartre proclaimed 'existence precedes essence' suggestive that the nature of the human being such as one's thought and emotions is fundamental than the mere fact of his existence [30], implicating of one being involved in meaning making process and valuing one's acts. Philosopher Kahlil Gibran also expresses similar note in his novel Broken Wings, where he relates to difficulty, and even rarity, of the successful search for meaning [31]. Also, Frederick Douglas, the famous American abolitionist says, 'if there is no struggle, there is no progress' [32]. A large number of researchers have contributed in the study of meaning in life by using terminologies such as existential growth, existential meaning, and existential reevaluation that contributes to posttraumatic growth [33], [34], [16], [35]. These aforementioned information gives a vague idea about how posttraumatic growth and existential thinking are related to each other.

\section{METHOD}

The participants were 150 young adults of age range 20 to 30 years belonging to various professions from Bengaluru, India. The sample were selected based on the typicality that the sample being picked is a good representation of a population that has experienced a traumatic event in the past. They included $61 \%$ of females and $39 \%$ of males, all being unmarried. The traumatic event experienced included physical Illness $(n=28)$, mental illness $(n=37)$, bereavement $\quad(n=32)$, relationship break-up $(n=50)$, negative childhood experience ( $n=48)$, accidents-producing injury $(n=20)$, recovery from substance abuse $(n=7)$, physical assault $(n=23)$, sexual assault $(n=14)$, separation from a close one $(n=36)$, academic problems $(n=25)$, natural causes- Earthquake, Tsunami $(n=0)$, combat $(n=1)$, inappropriate parenting styles $(n=27)$, divorce of parent $(n=3)$, plane crashes and Shootings $(n=0), \quad$ and miscellaneous $(n=19)$. The severity of the traumatic event experienced by the individuals were moderately severe (35\%) and highly severe (31\%), followed by extremely severe attaining to $13 \%$ of individuals. $10 \%$ of participants rated mildly severe and slightly severe and only $1 \%$ of participants rated not at all severe.

\section{MEASURES}

Posttraumatic Growth Inventory (PTGI)- is a 21-item measure answered on 5-point Likert scale ranging from 0 (I didn't experience this change as a result of my crisis) to 5 (I experienced this change to a very great degree as a result of my crisis). Participants rate on the degree to which change occurred as a result of crisis experienced. PTGI consists of five factors: Factor I: Relating to Others, Factor II: New Possibilities, Factor III: Personal Strength, Factor IV: Spiritual Change, and Factor V: Appreciation of Life. The scale yields a global score as well as individual factor scores. The scale showed internal consistency (Cronbach's alpha is 90 ) and test-retest reliability ( $r=0.65$ to 0.71 ).

Scale for Existential thinking (SET) is an 11-item measure answered on a 6-pont Likert scale ranging from 1 (no or rarely) to 6 (I don't know), with scores ranging from 11 to 55. Participants rate how often they engage in various existential thinking behaviour. The scale showed internal consistency (Cronbach's alpha is 0.95 ).

\section{PROCEDURE}

Inform consent was given to those individuals who had experienced trauma in the past and who were interested in 
participating in the study. Before commencing with the administration, rapport was established with the participants and instructions stating 'this is a questionnaire where you need to tick mark your responses based on your past traumatic event, if there are multiple traumatic events in your life, choose the one that was most stressful and keep that in mind while responding". Further, posttraumatic growth and existential thinking scales were given in randomized order.

\section{RESULTS}

The first step in the analysis was to find out, the most frequently reported trauma by the participants, which resulted in relationship break-up (33\%), negative childhood experience (32\%) being at the uppermost followed by mental illness (24.6\%), and separation from a closed one (24\%). As majority of participants opted more than one traumatic event (I.e. in more than one category) which justified our approach in identifying the different type of trauma experienced by the participants rather than comparing types of traumatic event. Also, the severity of the traumatic experience rated by the participants were highly severe $(31 \%)$ and moderately severe $(35 \%)$. Further means, standard deviation and correlation coefficients were performed to find out the relationship between posttraumatic growth $(M=67.7, S D=16.9)$ and existential thinking $(M=37.2, \mathrm{SD}=10.6)$, Pearson productmoment correlation was used. The results indicated a significant positive correlation between posttraumatic growth and existential thinking $(r=0.432, n=150, \quad p<0.01)$ as represented in table $I$.

TABLE I

MEANS, STANDARD DEVIATIONS AND CORRELATION COEFFICIENTS OF POSTTRAUMATIC GROWTH (PTG) AND EXISTENTIAL THINKING (ET)

\begin{tabular}{lccc} 
& \multicolumn{2}{c}{ Std. } \\
Variables & Means & Deviations & $\alpha$ \\
\hline PTG & 67.74 & 16.941 & $0.432^{* *}$ \\
ET & 37.28 & 10.601 & \\
Sig. & & 0.000 \\
N & & 150 \\
\hline **. Correlation is significant at the 0.01 level (2-tailed).
\end{tabular}

Additionally, linear regression analysis was used to see the impact of posttraumatic growth on existential thinking. The results revealed that posttraumatic growth could statistically predict existential thinking, $F(1,148)=34.002, p<0.01$ and posttraumatic growth accounted for $18.3 \%$ of the explained variability in individuals who involved in existential thinking as represented in table II.
TABLE II

REGRESSING POSTTRAUMATIC GROWTH (PTG) ON EXISTENTIAL THINKING (ET)

\begin{tabular}{cccccc}
\hline Variables & B & Std.Error & Beta & T & Sig. \\
& & & & & \\
\hline ET & 18.958 & 3.238 & & 5.854 & 0.000 \\
& & & & & \\
PTG & 0.270 & 0.046 & 0.432 & 5.831 & 0.000 \\
& & & & & \\
\hline
\end{tabular}

Note: $\mathrm{R}=0.432, \mathrm{R} 2=0.187, \mathrm{~F}=34.002, \mathrm{df}=1$

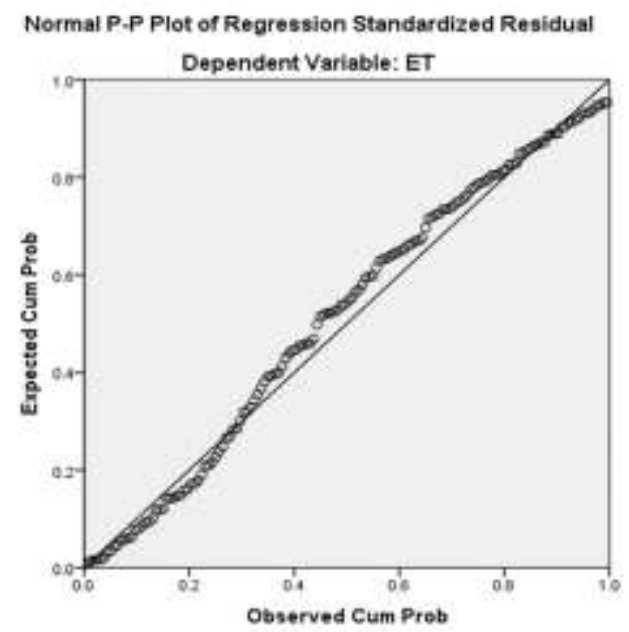

Fig. 1 represents scatterplot of regressing posttraumatic growth on existential thinking.

\section{DISCUSSION}

Posttraumatic growth literature has been rampantly explored since the initial formation [10]. Most studies on posttraumatic growth have been conducted on young adults [36], [9]. As they are more susceptible to mental illness and go through high stress and transition, where one is pulled away from their comfort zone and acquires new responsibilities [37]. A review of these have highlighted several factors associated with the development of posttraumatic growth including spirituality [11], demographics [10], and Personality [38]. A large body of researchers have linked posttraumatic growth with existential thinking aspects in terms of meaning in life, meaning-making process, existential growth, existential meaning, and existential re-evaluation [34], [16], [33], [35].

The current findings of the study revealed a significant positive correlation between posttraumatic growth and existential thinking. This suggests that individuals who have high levels of posttraumatic growth are prone to have high levels of existential thinking. This might be due to the fact that, those individuals in their posttraumatic period would involve in intense ruminations or cognitive processing regarding the traumatic experience, and that would prompt them to think in existential ways [15]. Also, inferring from the demographic details given by the participants. Those participants who have undergone multiple trauma showed 
higher level of posttraumatic growth when compared to pretrauma life. This is analogous to model of discontinuous change [39], wherein, it describes three possible outcomes when faced with challenging circumstances. Among them one such is higher level of functioning after experiencing trauma which determines thriving. Also, this scenario can be observed in Viktor E. Frankl's Man's search for Meaning, where Frankl experiences tremendous torture in the concentration camps which led to his discovery of logotherapy, a form of existential therapy that focus on meaning of human existence as well as one's search for meaning [7]. Thus, it reveals that posttraumatic growth could lead to existential thinking.

Further, linear regression analysis was performed, that revealed the impact of posttraumatic growth on existential thinking. This revelation is consistent with previous study [40] on bereavement and existential awareness which found that bereaved spouses showed varied degree of existential awareness. This might be due to the core beliefs and assumptions one had about the self and world, are shattered and the individual may involve in contemplating why this happened, what was the reason and what is the meaning [10], [11], [25]. Thus, the individual would involve in existential reevaluation by comprehending the traumatic experience in the context of anguish and agony [16]. As humans are meaning making animals and traumatic events have a major impact on survivors' assumption about meaning. Further leading to existential meaning and growth [35].

As Friedrich Nietzsche [27] says "that which does not kill us, make us stronger" and posttraumatic growth has revealed to prevent suicidal ideation [41]. Reference [42] suggested that posttraumatic growth lead to a positive personality change, as individuals develop to see life in new perspectives and begin to have positive psychological changes such as personal strength, new possibilities, spiritual and existential growth, and appreciation for life [10]. Thus, posttraumatic growth has an impact on existential thinking and from the results, it has accounted for $18.3 \%$ of explained variability and the remaining $57 \%$, might be due to the individuals' personality factors such as education, coping strategy, intellect, adaptation abilities, optimism about the traumatic event, and cognitive processing [38], [43], [15]. Therefore, it is clearly seen that individuals who have experienced a traumatic event have involved in existential thinking process. Even though the level of existential thinking varies among people. The fact, that individuals ponder about the fundamental concerns of humans' existence and involve in meaning-making process determines existential thinking.

\section{LIMITATIONS AND FUTURE DIRECTIONS}

Inferring from these studies and associating with present study we could see how posttraumatic growth plays a role in one's life leading to existential thinking. Many studies have shown that posttraumatic growth can prevent suicidal ideations, posttraumatic stress disorder (PTSD) and depression. Even though Calhoun and Tedeschi (2004) have accentuated that distress co-occurs along with growth, suggesting that posttraumatic growth is independent of occurrence. Thus, this particular concept can be implied in various clinical interventions as posttraumatic stress disorder (PTSD) typically do not take the account of potential for posttraumatic growth, as well as existential therapy do not look for the root cause that makes an individual think in existential ways.

Second, to promote well-being and growth. Many adults, kids and other who live in the border region as well as those in the army are exposed to frequent terrors, shootings, existential crisis and mayhem in life. Thus, by making them understand about these aspects and building hope in them, could bring about humanity among those who have lost. As Jean PaulSartre articulates existentialism is a humanism.

Third, to further build a model and a theory which would enhance our understanding as to why human's ricochet to existential aspects even though existence is the predominant survival instinct. What are the other aspects that makes human being think in existential ways when faced with challenging circumstances.

Limitations haunt us, as well as provides opportunities for further study. One such limitations when dealing with trauma are memories. Memories have different qualities after time/situation has passed. Thus, one of the drawback of the study is that it didn't mention the time period of when the traumatic event took place. Most of the researchers have chosen single trauma and only a few of them have taken multiple traumas in their study. Thus, the disadvantage of taking multiple traumas is that we could not derive the understanding of each trauma in relationship to growth. Lastly, the present study chose only one variable to see the impact of posttraumatic growth on existential thinking and didn't discuss about other contributing factors that might lead to existential thinking other than posttraumatic growth.

\section{ACKNOWLEDGMENT}

We would like to express our deepest gratitude to Department of Psychology, Jain University for the lasting support and encouragement. Also, to Dr. Guneet Inder Jit Kaur, Coordinator of Psychology Department, Jain University for supervision and unconditional motivation. We would like to thank our participants who took their precious time to share their experiences. Lastly, family and friends who endured our anxious venting and supported us throughout that encouraged to complete this work.

\section{REFERENCES}

[1] Slyke, J. V. (2014). Post-traumatic Growth. Naval Center for Combat \& Operational Stress Control. Retrieved from http://archieve.org/stream/PTGWhitePaperFinal/PTG_WhitePapeFinal_ djvu.tx

[2] Krause, N. (2004). Lifetime trauma, emotional support, and life satisfaction among older adults. The Gerontologist, 44(5), 615-623. Retrieved from https://doi.org/10.1093/geront/44.5.615 
[3] Substance Abuse and Mental Health Services Administration (2012). Trauma and Justice Strategic Initiative. (pp.2) Rockville, MD: SAMHSA

[4] Robinson, L., Smith, M. M.A., \& Segal, J. (2015). Emotional and Psychological Trauma: Symptoms, Treatment, and Recovery. Retrieved from: http://www.helpguide.org/articles/ptsdtrauma/emotional-andpsychological-trauma.htm

[5] Yalom, I. D. (1980). Existential Psychotherapy. New York: Basic Books

[6] Maslow, A. H. (1954). The Instinctoid Nature of Basic Needs. Journal of Personality,22 (3), 326-347. Doi:10.1111/j.1467. 1954.tb01136.x

[7] Frankl, V. (1962). Man's search for meaning: An introduction to logotherapy. Boston: Beacon press.

[8] Caplan, G. (1964). Principles of preventative psychiatry. New York: Basic Books

[9] Linley P. A., \& Joseph S. (2004). Positive Change Following Trauma and Adversity: A Review. Journal of Traumatic Stress, 17 (1), 11-21. https://doi.org/10.1023/B:JOTS.0000014671.27856.7e

[10] Tedeschi R. G., \& Calhoun L. G. (1960). A Posttraumatic Growth Inventory: Measuring the Positive Legacy of Trauma. Journal of Traumatic Stress, 9, 455-471. https://doi.org/10.1002/jts.2490090305

[11] Tedeschi, R. G., \& Calhoun, L. G. (2004). Posttraumatic Growth: Conceptual Foundations and Empirical Evidences. Psychological Inquiry, 15, 1-18 https://doi.org/10.1207/s15327965pli1501_01

[12] Sheikh A. (2008). Posttraumatic Growth in Trauma Survivors: Implication for practice. Counselling psychology Quarterly, 21(1), 8597 https://doi.org/10.1080/09515070801896186

[13] Cann, A., Calhoun, L. G., Tedeschi, R. G., \& Solomon, D. T. (2010). Posttraumatic growth and depreciation as independent experiences and predictors of well-being. Journal of Loss and Trauma, 15, 151-166.

[14] Schaefer, J. A., \& Moos, R. H. (1992). Life crisis and personal growth. In B. N. Carpenter (Ed.), Personal coping: Theory, research, and application (pp. 149-170). Westport, CT: Praeger.

[15] Calhoun, L. G., Cann A., Tedeschi, R. G., \& McMillan, J. (2000). A correlational Test of the Relationship between posttraumatic growth, religion, and Cognitive processing. Journal of Traumatic stress, 13 (3). https://doi.org/10.1023/A:1007745627077

[16] Janoff-Bulma, R. (2004). Postraumatic growth: Three Explanatory Models. Psychological Inquiry, 15 (1), 30-34

[17] Folkman, S., \& Moskowitz, J. T. (2000). Positive Affect and the Other Side of Coping. American Psychologist,55(6), 647-654. Doi:10.1037/0003-066X0055.00

[18] Taylor, S., Kemeny, M., Reed, G.M., \& Grunewald, T.L. (2000). Psychological resources, positive illusions, and health. American Psychologist, 55 (1), 99-109. Doi: 10.1037/000.-066X.55.1.99

[19] Greenberg, M. (1995). Cognitive processing in trauma: The role of intrusive thoughts and reappraisals. Journal of Applied Social Psychology, 25, 1262-1296. https://doi.org/10.1111/j.1559-1816.1995.tb02618.x

[20] Van Deurzen, E. (2005). Philosophical background. In E. van Deurzen \& C. Arnold Baker (Eds.), Existential perspectives on human issues: A handbook for therapeutic practice $(\mathrm{pp}, 1-14)$. New York: Palgrave Macmillan

[21] Allan, B. A., \& Shearer C. B. (2012). A Scale for Existential Thinking. International Journal of Transpersonal Studies, 31(1),21-37 https://doi.org/10.24972/ijts.2012.31.1.21

[22] Hartelius, G., Caplan, M., \& Rardin, M. A. (2007). Transpersonal psychology: Defining the past, divining the future. The Humanistic Psychologist, 35(2), 1-26. doi:10.1080/08873260701274017

[23] Moos R.H., \& Schaefer J.A. (1986). Life Transitions and Crises. In: Moos R.H. (eds) Coping with Life Crises. The Springer Series on Stress and Coping. Springer, Boston, MA https://doi.org/10.1007/978-1-4684-7021-5

[24] Park, C.L., Cohen, L.H., \& Murch, R.L. (1996). Assessment and prediction of stress-related growth. Journal of Personality, 64 (1), 71105. Doi: 10.1111/j.1467.196.tb00815.x

[25] Janoff-Bulman, R. (1992). Shattered assumptions: Towards a new psychology of trauma. New York, NY, US: Free Press.
[26] Taylor, S. E., \& Brown, J. D. (1988). Illusion and well-being: A social psychological perspective on mental health. Psychological Bulletin, 103(2), 193-210. Doi: 10.1037/0033-2909.103.2.193 https://doi.org/10.1037/0033-2909.103.2.193

[27] Evans, Draw-Nay. (2010). Socrates as Nietzsche's Decadent in Twilight of the Idols. Philosophy and Literature, 34(2), 340-347. The Hopkins University Press. Doi:10.1353/phl.2010.0009 https://doi.org/10.1353/phl.2010.0009

[28] Bush, N. E., Skopp, N. A., McCann, R, \& Luxton, D. (2011). Posttraumatic Growth as Protection Against Suicidal Ideation After Deployment and Combat Exposure. Military Medicine, 176, 11:1215.

[29] Camus, A. (1991). The Myth of Sisyphus and Other Essays. pp. 123. New York: Vintage Books.

[30] Crowell, S. (2004). Existentialism, The Stanford Encyclopaedia of Philosophy. Metaphysics Research Lab: Stanford University. Retrieved from https://plato.stanford.edu/entries/existentialism

[31] Gibran, K. (1912). Broken Wings. White Cloud Press.

[32] Blassingame, J.W. (ED.). (1985). The Frederick Douglas papers. Series one: Speeches, debates, and interviews. Vol 3, 1855-63. New Haven, CT: Yale University Press

[33] Kashdan, T. B., \& Kane, J. Q. (2011). Posttraumatic distress and the presence of posttraumatic growth and meaning in life: Experiential avoidance as a moderator, 50 (1), 84-89. Doi: 10.1018/j.paid.2010.08.028

[34] Triplett, K. N., Tedeschi, R. G., Cann, A., Calhoun, L. G., \& Reeve, C. L. (2011). Posttraumatic Growth, Meaning in Life, and Life Satisfaction in Response to Trauma. Psychological Trauma: Theory, Research, Practice, and Policy. Doi: 10.1037/a0024204

[35] Reilly, R.C., Lee, V., Laux, K., \& Robitaille, A. (2017). Creating doorways: finding existential meaning and growth through the creative arts in the face of life-threatening illness. Creative practices for improving health and social inclusion. 5th International Health Humanities Conference, Sevilla 2016 (2017), p 279-289s

[36] Park, C. L., \& Helgeson, V. S. (2006). Introduction to the special Section: Growth Following Highly Stressful Life Events- Current Status and Future Directions. Journal of consulting and Clinical Psychology, 74 (5), 791-796.doi:10.1037/0022-006X.74.5.791

[37] Grace, B. (2013). Mental illness: Why young adults are most susceptible. Elite Daily. Retrieved from https://www.elitedaily.com/life/mental-illness-young-adults-susceptible

[38] Prati, G., \& Pietrantoni, L. (2009). Optimism, Social Support, and Coping Strategies as Factors Contributing to Posttraumatic Growth: A meta-Analysis, Journal of Loss and Trauma, 14(5), 364-388, doi:10.1080/1532502090272421

[39] O'Leary, V. E., \& Ickovics, J. R. (1995). Resilience and thriving in response to challenge: An opportunity for a paradigm shift in women's health. Women's Health: Research on Gender, Behavim and Policy, 1, 121-142.

[40] Yalom, I. D., \& Lieberman, M. A. (1991). Bereavement and heightened existential awareness. Psychiatry, 54, 334-345. https://doi.org/10.1080/00332747.1991.11024563

[41] Bush, N. E., Skopp, N. A., McCann, R, \& Luxton, D. (2011). Posttraumatic Growth as Protection Against Suicidal Ideation After Deployment and Combat Exposure. Military Medicine, 176, 11:1215.

[42] Jayawickreme, E., \& Blackie, Laura. E.R. (2014). Posttraumatic growth as positive personality change: evidences, controversies and future directions. European Journal of Personality, 28 (4), 312-331. Doi: 10.1001/per.1963

[43] Cadell, S., Regehr, C., \& Hemsworth, D. (2003). Factors contributing to posttraumatic growth: A proposed structural equation model. American Journal of Orthopsychiatry, 73(30), 279-287.doi:10.1037/0002-943273.3.279 
About Author (s):

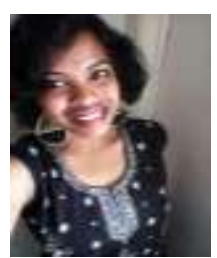

"It is absurd to live and yet we live. It is alright to die, yet we do not prefer death. It's a paradoxical embolism! An entity trying to unite the existential theatre". -Sahana, V.

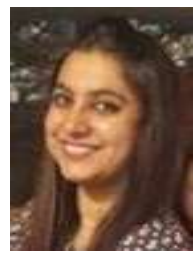

"In the sea of life, trauma may well represent the tremors, and yet, this accumulated traumatic energy in turn may lead to the shore of tranquillity again. Life's potential constructive tendency is existential truth."

- Dr. Guneet Inder Jit Kaur 